\title{
O (des)engajamento social na modernidade líquida: sobre participação social em saúde
}

\author{
Social (dis)engagement in liquid modernity: on social participation in \\ health
}

Marcela Miwa', Carla Ventura1

DOI: $10.1590 / 0103-1104202012722$

\begin{abstract}
RESUMO A modernidade líquida é caracterizada, sobretudo, pela fluidez e pelo derretimento das limitações da liberdade individual de escolher e agir, diluindo a importância de padrões, códigos, regras e referências sociais, estimulando o desejo, especialmente o desejo do consumo, impulsionado pelo predomínio da individualidade em detrimento de valores coletivos. É nesse cenário, caracterizado principalmente pela fluidez, crescente individualização e consequente desengajamento, que se precisa pensar a possibilidade e a efetividade da participação social nas questões de saúde. O presente ensaio pretende identificar possíveis formas de participação social em saúde em nível local, isto é, nas unidades de Atenção Primária à Saúde, e analisá-las sob a ótica da modernidade líquida, estudada por Zygmunt Bauman, no intuito de melhor compreender a dinâmica do (des)engajamento social. A leitura da realidade macrossocial, pela ótica da modernidade líquida, demonstrou-se recurso enriquecedor para a compreensão de como a fluidez nas interações, das sociedades consideradas pós-modernas, pode influenciar no envolvimento das pessoas na participação em saúde.
\end{abstract}

PALAVRAS-CHAVE Participação social. Conselhos de Saúde. Atenção Primária à Saúde.

\begin{abstract}
Liquid modernity is characterized, mainly, by its fluidity and the 'melting' of borders regarding the individual freedom to choose and act, diminishing the importance of patterns, codes, rules and social references, as well as stimulating the desire, especially for consumption, amplified by the predominance of individuality to the detriment of collective values. Thus, in this scenario, characterized by the fluidity and increasing individuality and disengagement, it is important to think about the possibility and effectiveness of social participation in health issues. This essay aims to identify possible paths for social participation in health at the local level, that is, Primary Health Care units, and analyze them based on the liquid modernity framework with the purpose of improving the understanding regarding the social (dis)engagement dynamics. The analysis of the macro social reality, in light of liquid modernity, proved to be a rich resource to understand how the fluidity in interactions of post-modern societies can influence the involvement of people in participation in health.
\end{abstract}

KEYWORDS Social participation. Health Councils. Primary Health Care.

1 Universidade de São Paulo

(USP) - São Paulo (SP),

Brasil.

marcelajmiwa@yahoo.

com.br 


\section{Introdução}

A participação social em saúde é considerada elemento importante para a prática democrática, atuando como estratégia para o combate às desigualdades sociais' ${ }^{1}$. Nessa perspectiva, a participação ativa em processos que moldam as vidas das pessoas é fundamental para o desenvolvimento humano ${ }^{2}$, uma vez que interfere em situações de inclusão social, lutas contra injustiças e reconhecimento de direitos ${ }^{3}$.

$\mathrm{Na}$ área da saúde, as manifestações políticas por direitos podem ser caracterizadas, principalmente, de duas formas: a) claimed participation, relacionada com movimentos sociais e ações de protestos; e b) invited participation, identificada como formas institucionalizadas de participação, geralmente por meio de conselhos de saúde ${ }^{4,5}$, que podem ser consultivos ou deliberativos. No caso brasileiro, nota-se a predominância dos conselhos deliberativos nos níveis federal, estadual ou municipal6. Já em alguns países da Europa, como, por exemplo, em Portugal, identificam-se conselhos de caráter mais consultivo ${ }^{\mathbf{7} 8}$.

No entanto, apesar da existência de canais de participação social em saúde e do reconhecimento da importância e da legitimidade do envolvimento dos cidadãos na condução da saúde pública, nem sempre o envolvimento e a participação dos cidadãos são efetivos ${ }^{4}$, talvez por uma falta de 'cultura participativa':

[...] entende-se que a construção de uma cultura participativa, que respeita a autonomia das pessoas e seus direitos demanda tempo, necessitando de um terreno propício para que as potencialidades possam florescer e se manifestar(908).

Entendemos que a construção dessa cultura participativa, além de tempo e terreno propício, necessita, fundamentalmente, de compromisso, por parte dos sujeitos, para que essa cultura possa persistir ao longo das gerações e das consciências. Contudo, como esperar comprometimento no contexto da 'modernidade líquida'?
Ninguém ficaria surpreso ou intrigado pela evidente escassez de pessoas que se disporiam a ser revolucionários: do tipo de pessoas que articulam o desejo de mudar seus planos individuais como projeto para mudar a ordem da sociedade ${ }^{10(12)}$.

\section{A modernidade líquida}

A modernidade líquida é caracterizada, sobretudo, pela 'fluidez'10. Segundo o sociólogo Zygmunt Bauman, o sólido possui dimensões claras e diminui a significação do tempo porque perdura ao longo da história. Em contrapartida, o líquido não se atém às formas, sofrendo mudanças quando submetido à pressão ${ }^{10}$, e, nesse contexto, o tempo adquire maior importância pela ideia de mobilidade e rapidez.

O capitalismo contemporâneo fomentou o 'derretimento' das limitações da liberdade individual de escolher e agir, diluindo a importância de padrões, códigos, regras e referências sociais, estimulando o desejo, especialmente o do consumo, impulsionado pelo predomínio da individualidade em detrimento de valores coletivos.

\begin{abstract}
A desintegração da rede social, a derrocada das agências efetivas de ação coletiva, é recebida muitas vezes com grande ansiedade e lamentada como 'efeito colateral' não previsto da nova leveza e fluidez do poder cada vez mais móvel, escorregadio, evasivo e fugidio. Mas a desintegração social é tanto uma condição quanto um resultado da nova técnica de poder, que tem como ferramentas principais o desengajamento e a arte da fuga ${ }^{10(21-2)}$.
\end{abstract}

É nesse cenário, caracterizado principalmente pela fluidez, crescente individualização e consequente desengajamento ${ }^{10-12}$, que precisamos pensar a possibilidade e a efetividade da participação social nas questões de saúde.

A participação política é considerada fluida e dinâmica ${ }^{13}$, entretanto, essa 'fluidez', somada 
à 'liquidez' das sociedades consideradas pós-modernas, pode tornar a participação social demasiadamente diáfana para assegurar algum tipo de envolvimento ou compromisso em longo prazo.

Considerando que o direito à saúde é assegurado em âmbito local14, o presente ensaio pretende identificar possíveis formas de participação social em saúde em nível local, isto é, nas unidades de Atenção Primária à Saúde - uma vez que são consideradas instâncias mais próximas dos cidadãos e nas quais, teoricamente, as pessoas poderiam ter mais espaço para manifestarem suas demandas - e analisá-las sob a ótica da modernidade líquida, estudada por Zygmunt Bauman, no intuito de ampliar a discussão sobre o tema e trazer novos elementos para melhor compreender a dinâmica do (des)engajamento social.

\section{Conselhos Locais de Saúde no Brasil - comunidades éticas em tempos líquidos}

Os Conselhos Locais de Saúde (CLS) são instâncias formais de participação social, geralmente associadas a unidades de Atenção Primária à Saúde ${ }^{15}$, e seguem os mesmos preceitos dos demais conselhos de saúde, que são: avaliar e fiscalizar serviços e recursos em saúde, com a característica de serem "mais porosos às demandas comunitárias"16(680). No entanto, sua existência não é prevista pela Lei no ${ }^{\circ} 8.142^{6}$, que trata da participação da comunidade na gestão do Sistema Único de Saúde (SUS). A Resolução $\mathrm{n}^{\circ} 453$, de $2012^{17}$, que visou reestruturar e reformular o funcionamento dos conselhos, citou os CLS, entretanto, não estabeleceu regras sobre sua organização e formas de operacionalização. Sua instituição e legislação ficaram a cargo dos próprios municípios ${ }^{18}$, fato que pode acarretar descompassos na experiência da participação de uma localidade para outra.

Por se tratar de um espaço formal de participação social, que visa ao bem público em saúde, pela perspectiva da modernidade líquida, podemos entender os CLS nos moldes das comunidades éticas, caracterizadas pelo compromisso social e planejamento em longo prazo:

A comunidade que procuram seria uma comunidade 'ética' [...] Teria que ser tecida de compromissos de longo prazo, de direitos inalienáveis e obrigações inabaláveis [...] E os compromissos que tornariam ética a comunidade seriam do tipo do 'compartilhamento fraterno', reafirmando o direito de todos a um seguro comunitário contra os erros e desventuras que são os riscos inseparáveis da vida individua|11(68).

"Certeza, segurança e proteção"11(68) deveriam ser estímulos para uma maior participação social nos CLS, contudo, mesmo tendo sua existência garantida por lei ou decreto municipal, nem sempre os CLS conseguem ser eficazes. Primeiro, porque nem todas as unidades de saúde apresentam CLS, pois dependem da iniciativa dos gestores e profissionais da unidade em conjunto com a comunidade local. Lembrando que uma das tendências do poder, na modernidade líquida, é o 'desengajamento' e a 'arte da fuga'10, não é de se estranhar certa displicência das autoridades competentes (locais, regionais, estaduais e federais) em solidificar a participação social nas instâncias mais próximas e acessíveis aos cidadãos. Segundo que, somado à postura, por vezes, evasiva ante a responsabilidade (que exige presença e engajamento), os CLS deparam-se com outros obstáculos: a carência de uma cultura participativa e a imprecisão sobre as funções inerentes aos CLS.

Mesmo que já estejam instituídos, o desconhecimento sobre as atribuições e responsabilidades desses conselhos pode atravancar sua atuação e a participação social em seu espaço interno. Diversos estudos debruçaram-se sobre as dificuldades de atuação enfrentadas pelos membros de CLS, identificando, por exemplo, falta de conhecimentos sobre as competências do CLS ${ }^{16,19}$; baixa confiança e receptividade 
entre profissionais de saúde e usuários ${ }^{\mathbf{2 0}}$; assim como comportamento individualista e imediatista ${ }^{15,21}$ de alguns membros.

Este último fator, comportamento individualista e imediatista, seria apenas mais um reflexo do comportamento na sociedade líquida geral, marcada pela prevalência de interesses individuais voltados ao atendimento dos desejos e consumo, em que a velocidade das respostas às demandas é que confere maior 'positividade' às relações.

Outro fator que pode dificultar a participação social nos CLS e, consequentemente, prejudicar seu desempenho é a comunicação ${ }^{22}$. O uso de termos técnicos ou mesmo de uma 'linguagem codificada'23 pode desestimular o envolvimento dos usuários nas reuniões e ações dos CLS, acentuando a falta de identidade com as questões discutidas e agravando o desengajamento. Somada a isso, a potencial

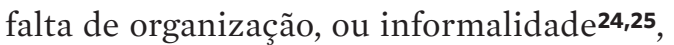
também pode obstaculizar o poder de influência desses conselhos, uma vez que torna as relações fluidas demais, desestimulando o comprometimento em longo prazo.

Embora muitos estudiosos reconheçam o potencial dos CLS como espaços privilegiados para o exercício da democracia participati$\mathrm{va}^{16,26,27}$, essa relação intrincada, entre usuários e CLS, impacta no próprio reconhecimento dos CLS como espaços para apresentação de demandas e resolubilidade. A população muitas vezes ignora a existência do CLS na unidade que frequenta ${ }^{16,19,20}$, relegando-o a um espaço de certa invisibilidade ${ }^{4}$, tornando-o pouco atraente à participação popular.

\section{Formas 'não convencionais' de participação - a emergência de comunidades estéticas}

Em contraposição às comunidades éticas, que buscam compromissos em longo prazo, existem as 'comunidades estéticas', caracterizadas pela espontaneidade e fugacidade dos vínculos sociais.

\begin{abstract}
Qualquer que seja o foco, a característica comum das comunidades estéticas é a natureza superficial, perfunctória e transitória dos laços que surgem entre seus participantes. Os laços são descartáveis e pouco duradouros [...]. Uma coisa que a comunidade estética definitivamente não faz é tecer entre seus membros uma rede de 'responsabilidades éticas' e, portanto, de 'compromissos a longo prazo'. [...] os laços das comunidades estéticas devem ser 'experimentados', e experimentados no ato - não levados para casa e consumidos na rotina diária11(67-8).
\end{abstract}

Essa 'fluidez' das comunidades estéticas parece ser uma das principais marcas de outra importante forma de participação social em saúde: as ações de protesto.

As ações de protesto podem insurgir em quaisquer níveis dos serviços de saúde, desde o fechamento de maternidades até os serviços da atenção primária, e emergem "enquanto manifestações 'momentâneas' e 'espontâneas' de oposição ou de descontentamento social"28(3) de atores coletivos. Mesmo que essas ações não garantam resultados estáveis nas políticas públicas, possuem o mérito de publicizar necessidades e discordâncias das populações afetadas pelas políticas em saúde?.

Dentro da lógica da modernidade líquida, as ações de protesto aparentam ser mais eficazes que mecanismos formais de participação, como os CLS, por serem rápidas, centradas em uma causa específica e por mobilizarem, agilmente, considerável número de pessoas. Todavia, assim que as reivindicações são atendidas, a força das ações de protesto se dissolve, deixando uma lacuna no engajamento em longo prazo, e prejudicando, de certa forma, o aprimoramento de uma cultura participativa.

Essa efemeridade das ações de protesto faz com que as associemos muito mais à identificação individual a uma causa específica do que a uma identidade, enquanto grupo social, capaz de estabelecer vínculos e compromissos coletivos. 
Outra forma de participação em saúde, que, por vezes, acompanha as ações de protesto são as petições ou abaixo-assinados que, assim como os protestos, perdem sua força de engajamento no momento em que suas solicitações são satisfeitas.

Em Portugal, por exemplo, são também reconhecidas outras duas modalidades não convencionais de participação social em saúde, por ora não muito exploradas por estudos realizados no Brasil: as Ligas de Amigos e as Associações de Doentes.

As Ligas de Amigos tiveram início em 1988. Conforme a Revista do Município de Vila Nova de Gaia29(11), a primeira Liga de Amigos de um Centro de Saúde surgiu por iniciativa do médico Miguel Paulo Barrosa Pinto de Miranda, como uma instituição sem fins lucrativos, voltada ao apoio de idosos e isolados em domicílio. As Ligas de Amigos caracterizam-se pelo voluntariado, prestação de serviços assistenciais e de apoio aos usuários dos serviços de saúde, inclusive nas unidades de atenção primária.

Em livro comemorativo dos 20 anos da Liga dos Amigos do Hospital de Ponta Delgada ${ }^{30}$, nota-se que, em muitos dos depoimentos dos membros dessa Liga, há a correlação entre voluntariado e princípios religiosos, como fraternidade, benevolência e gratidão. Nesse sentido, não é possível estabelecer uma associação direta entre Liga de Amigos e movimento social organizado, uma vez que o foco não é exercer pressão para mudança ${ }^{\mathbf{2 8}}$.

Entretanto, devido à proximidade entre os usuários dos serviços e os voluntários das Ligas, é admissível identificar, nessa relação, um potencial dessas Ligas para o advocacy ${ }^{\mathbf{3 1}}$, não apenas como representantes dos interesses dos usuários, mas também como estimuladoras do envolvimento dos próprios usuários na defesa de seus direitos em saúde. De acordo com Vieira e Silva ${ }^{32(179),}$

[...] o problema da representação enquanto 'advocacy' é que, quando desligada de uma exigência de interlocução e desenvolvimento de capacidades agenciais nos representados, pode facilmente desaguar no paternalismo ou na mera caridade.

Essa atuação mais próxima aos usuários aliada ao potencial de advocacy talvez sejam os elementos necessários para vislumbrarmos a transformação de comunidades estéticas para comunidades éticas, em que o envolvimento dos próprios usuários, na defesa de seus direitos, propicie maior consciência da importância do engajamento em longo prazo. Os CLS deveriam apresentar o mesmo potencial, porém, como mencionado acima, os conselhos enfrentam diversas dificuldades para se tornarem acessíveis aos cidadãos.

Considerando ainda a ideia de advocacy, outro grupo reconhecido pela luta em defesa dos interesses de parcelas específicas da população, capaz ainda de estimular o engajamento de seus representados, são as Associações de Doentes, que, consoante Matos e Serapioni ${ }^{7(5)}$, desempenham "um papel extremamente relevante na representação e na defesa dos pacientes”. Contudo, essas Associações apresentam uma atuação mais voltada à doença e a aspectos ligados ao diagnóstico, à terapia, ao tratamento, à pesquisa etc., restringindo a expressão da identidade coletiva apenas aos aspectos da doença, não estimulando vínculos e compromissos éticos que extrapolem a pauta patológica.

Em uma sociedade em que o desengajamento é atributo recorrente, enfocar apenas determinada enfermidade pode reduzir o interesse social daqueles que não são afetados pelo problema. Segundo Bauman10(83), "os problemas privados não se tornam questões públicas pelo fato de serem ventilados em público".

Nessa perspectiva, é importante advertir que este ensaio não questiona a legitimidade dessas formas de participação social (CLS, ações de protesto, Ligas de Amigos, Associações de Doentes), uma vez que seu intuito é refletir como essas formas de participação podem estimular ou facilitar o (des)engajamento social na luta por direitos em saúde, considerando-se o contexto da modernidade líquida. 


\section{Participação em saúde como 'tomar parte' - a sociedade individualizada}

Reconhece-se ainda uma forma mais sutil de participação social em saúde, denominada 'tomar parte', que, em linhas gerais, entende que durante o encontro clínico, entre usuário e profissional de saúde/conhecimento biomédico, a interação permite a reconfiguração da relação entre saber científico e a experiência e saberes sobre saúde do sujeito/usuário, negociando a autoridade e a força do conhecimento médico ${ }^{33}$.

Nesse sentido, percebe-se que esse 'tomar parte' repousa sobre a premissa da correlação de forças entre os envolvidos, na dinâmica de uma microfísica do poder ${ }^{34}$ durante o encontro clínico. Trata-se de uma dimensão pouco visível que, no entanto, deve ser reconhecida como elemento significativo para a manifestação de demandas e exercício da democracia deliberativa, diminuindo, de certa forma, distâncias epistemológicas.

O que chama atenção nessa forma de participação é que ela se sustenta, predominantemente, no posicionamento de representantes individuais de forças: usuário $\mathrm{x}$ conhecimento médico, ou usuário x sistema de saúde. Assim sendo, não há envolvimento direto ou explícito de uma coletividade, mas ações pontuais de resistência e pressão aos meios convencionais de saúde. "Tanto as condições como as narrativas sofrem um implacável processo de 'individualização"'12(13), e por serem vistas como questões meramente privadas, essas demandas em saúde correm o risco de não ganharem a devida atenção social, dificultando a luta por direitos.

\section{Participação em saúde - ética do social}

No que diz respeito às formas de participação estudadas, a falta de engajamento ou compromisso, na participação em saúde, reflete a fluidez das interações na modernidade líquida baumaniana. Os sujeitos reúnem-se em torno de um interesse comum, momentaneamente, contudo, parecem não criar vínculos duradouros com a causa que defendem ou com os espaços que ocupam. A compreensão dessa dinâmica fluida pode contribuir para um melhor entendimento do que os teóricos intitulam como 'desafios da participação’ em saúde ${ }^{7,22,35}$, tão recorrentes nos estudos sobre o tema, assim como, repensar o próprio conceito de participação e as novas formas de fazer política.

Cientes das peculiaridades da modernidade líquida, desponta-se a questão: se se vive em uma sociedade regulada pela fluidez e individualidade, por que as pessoas deveriam se preocupar com assuntos coletivos? Talvez porque, ao se considerar a presença e as necessidades do 'outro', preserva-se a dimensão ética que sustenta a vida social.

Em conformidade com Bauman 12(96):

Quando Deus perguntou a Caim onde estava Abel, Caim replicou, zangado, com outra pergunta: 'Sou por acaso o guardião do meu irmão?' O maior filósofo ético do nosso século Emmanuel Levinas comentou que dessa pergunta zangada de Caim começou toda a imoralidade. É claro que sou o guardião de meu irmão; e sou e permaneço uma pessoa moral enquanto não pergunto por uma razão especial para sê-lo. Quer eu admita, quer, não, sou o guardião do meu irmão porque o bem-estar do meu irmão 'depende' do que eu faço ou do que me abstenho de fazer. E sou uma pessoa moral porque reconheço essa dependência e aceito a responsabilidade que ela implica. [...] A dependência de meu irmão é o que me faz um ser ético. A dependência e a ética estão juntas, e juntas elas caem.

Nesse ponto de vista, a participação social e a construção de uma cultura participativa no âmbito da saúde, além de serem uma luta por direitos, configuram-se como um imperativo 
*Orcid (Open Researcher and Contributor ID). ético do social pela segurança e proteção diante da insegurança e vulnerabilidade gerados pela modernidade líquida.

\section{Considerações finais}

Este estudo, mais do que versar sobre as peculiaridades das formas participação social em saúde na Atenção Primária à Saúde, teve o intuito de enriquecer a discussão sobre o próprio conceito de participação social em saúde em tempos de inconstância e crescente individualização na modernidade líquida.

A leitura da realidade macrossocial, pela ótica da modernidade líquida, demonstrou-se recurso enriquecedor para a

\section{Referências}

1. World Health Organization. Community participation in local health and sustainable development: approaches and techniques [internet]. Genebra: WHO; 2002 [acesso em 2016 out 28]. Disponível em: http://www. euro.who.int/_data/assets/pdf_file/0013/101065/ E78652.pdf.

2. United Nations Development Programme. Human development report 2016: human development for everyone [internet] New York: UNDP; 2016 [acesso em 2019 jun 20]. Disponível em: http://hdr.undp.org/ sites/default/files/HDR2016_EN_Overview_Web.pdf.

3. Gohn MG. Teorias sobre a participação social: desafios para a compreensão das desigualdades sociais. Cad. CRH. [internet]. 2019 [acesso em 2019 nov 21]; 32(85):63-81. Disponível em: http://www.scielo.br/ pdf/ccrh/v32n85/0103-4979-ccrh-32-85-0063.pdf. compreensão dos mecanismos da participação social, especialmente, no que diz respeito ao engajamento dos sujeitos. A fluidez nas interações, nas sociedades consideradas pós-modernas, é um fator que deve ser relevado na análise do envolvimento das pessoas na participação em saúde, mesmo que, no caso, esteja se debruçando sobre realidades demasiadamente locais, como a participação social na Atenção Primária à Saúde.

\section{Colaboradoras}

Miwa M (0000-0001-5809-3068)* e Ventura C (0000-0003-0379-913X)* contribuíram igualmente para a elaboração do manuscrito.
4. Miwa MJ, Serapioni M, Ventura CAA. A presença invisível dos Conselhos Locais de Saúde. SaúdeSoc. [internet]. 2017 [acesso em 2017 jun 27]; 26(2):411-423. Disponível em: http://www.scielo.br/pdf/sausoc/ v26n2/1984-0470-sausoc-26-02-00411.pdf.

5. Cornwall A, Schattan V, Coelho P. Spaces for Change? The Politics of Citizen Participation in New Democratic Arenas [internet]. London: Zed Book; 2007 [acesso em 2016 out 28]. Disponível em: https://www. researchgate.net/publication/260388966_Spaces_ for_Change_The_Politics_of_Citizen_Participation_ in_New_Democratic_Arenas.

6. Brasil. Lei ${ }^{\circ}$ 8.142, de 28 de dezembro de 1990. Dispõe sobre a participação da comunidade na gestão do Sistema Único de Saúde e sobre as transferências intergovernamentais de recursos financeiros na área 
saúde. Diário Oficial da União [internet]. 29 Dez 1990 [acesso em 2016 jul 27]. Disponível em: http://www. planalto.gov.br/ccivil_03/leis/L8142.htm.

7. Matos AR, Serapioni M. O desafio da participação cidadã nos sistemas de saúde do Sul da Europa: uma revisão da literatura. Cad. Saúde Pública (Online). [internet]. 2017 [acesso em 2017 jul 17]; 33(1):111. Disponível em: http://www.scielo.br/pdf/csp/ v33nl/1678-4464-csp-33-01-e00066716.pdf.

8. Serapioni M, Matos AR. Saúde, Participação e Cidadania: experiências do Sul da Europa. Coimbra: Edições Almedina; 2014. 250 p.

9. Ventura CAA, Miwa MJ, Serapioni M, et al. Cultura participativa: um processo de construção de cidadania no Brasil. Interface (Botucatu, Online). [internet]. 2017 [acesso em 2018 mar 20]; 21(63):907920. Disponível em: http://www.scielo.br/pdf/icse/ v21n63/1807-5762-icse-1807-576220150941.pdf.

10. Bauman Z. Modernidade líquida. Rio de Janeiro: Jorge Zahar; 2001. 280 p.

11. Bauman Z. Comunidade: a busca por segurança no mundo atual. Rio de Janeiro: Jorge Zahar; 2003. 144 p.

12. Bauman Z. A Sociedade individualizada: vidas contadas e histórias vividas. Rio de Janeiro: Jorge Zahar; 2008. 324 p.

13. Escorel S, Arouca LE. Democracia e participação: para além das dicotomias. Saúde debate [internet]. 2016 [acesso em 2017 fev 18]; 40(esp):39-48. Disponível em: http://www.scielo.br/pdf/sdeb/v40nspe/01031104-sdeb-40-spe-0039.pdf.

14. Dallari SG. O direito à saúde. Rev. saúde pública (Online). [internet]. 1988 [acesso em 2017 fev 18]; 22(1):5763. Disponível em: http://www.scielo.br/pdf/rsp/ v22n1/08.pdf.

15. Bispo Jr. JP, Martins PC. Envolvimento comunitário na Estratégia de Saúde da Família: dilemas entre institucionalização e efetiva participação. Phy- sis (Rio J.). [internet]. 2012 [acesso em $2017 \mathrm{fev} \mathrm{19];}$ 22(4):1313-1332. Disponível em: http://www.scielo. br/pdf/physis/v22n4/a04v22n4.pdf.

16. Lisboa EA, Sodré F, Araújo MD, et al. Conselhos locais de saúde: caminhos e (des)caminhos da participação social. Trab. educ. saúde. [internet]. 2016 [acesso em 2016 out 20]; 14(3):679-698. Disponível em: http://www.scielo.br/pdf/tes/v14n3/1981-7746tes-1981-7746-sol00013.pdf.

17. Brasil. Ministério da Saúde, Conselho Nacional de Saúde. Resolução $\mathrm{n}^{\circ}$ 453, de 10 de maio de 2012. Define diretrizes para instituição, reformulação, reestruturação e funcionamento dos Conselhos de Saúde. Diário Oficial da União [internet]. 11 Maio 2012 [acesso em 2016 jul 27]. Disponível em: http://bvsms.saude.gov. br/bvs/saudelegis/cns/2012/res0453_10_05_2012. html.

18. Nogueira FCP, Lima LHO, Wolfovitch RGS, et al. Implantação de um conselho local de saúde: desafios da prática do controle social. Rev. baiana saúde pública. 2008; 32(1):104-110.

19. Busana JA, Heidemann TSB, Wendhausen ALP. Participação popular em um conselho local de saúde: limites e potencialidades. Texto \& contexto enferm. 2015; 24(2):442-449.

20. Domitrovic N, Araújo MD, Quintanilha BC. O papel do mediador no incentivo à participação das comunidades nas ações de promoção da saúde. Psicol. teor. prát. [internet]. 2013 [acesso em 2016 out 21]; 15(1):8191. Disponível em: http://pepsic.bvsalud.org/pdf/ptp/ v15n1/07.pdf.

21. Mielke FB, Cossetin A, Olschowsky A. O conselho local de saúde e a discussão das ações de saúde mental na Estratégia Saúde da Família. Texto \& contexto enferm. [internet]. 2012 [acesso em 2016 out 21]; 21(2):387-394. Disponível em: http://www.scielo.br/pdf/tce/v2ln2/a17v2ln2.pdf.

22. Cruz PJSC, Vieira SCR, Massa NM, et al. Desafios para a participação popular em saúde: reflexões a partir da educação popular na construção de conse- 
lho local de saúde em comunidades de João Pessoa, PB. Saúde Soc. [internet]. 2012 [acesso em 2016 out 20]; 21(4):1087-1100. Disponível em: http://www.scielo.br/pdf/sausoc/v2ln4/v2ln4a25.pdf.

23. Craco PF, Almeida MCP. A participação popular nas comissões locais de saúde: mostrando vidas, contando lutas. Rev. bras. enferm. [internet]. 2004 [acesso em 2016 out 20]; 57(2):188-192. Disponível em: http:// www.scielo.br/pdf/reben/v57n2/allv57n2.pdf.

24. Oliveira AMC, Dallari SR. Participação social no contexto da Atenção Primária em Saúde: um estudo de caso das Comissões Locais de Saúde do SUS de Belo Horizonte. Physis (Rio J.). [internet]. 2015 [acesso em 2016 out 21]; 25(4):1059-1078. Disponível em: http://www.scielo.br/pdf/physis/v25n4/0103-7331 -physis-25-04-01059.pdf.

25. Lopes MLS, Almeida MJ. Conselhos Locais de Saúde em Londrina (PR): realidade e desafios. Saúde debate. $2001 ; 25(59): 16-28$.

26. Coelho VS, Ferraz A, Fanti F, et al. Mobilização e participação: um jogo de soma zero? Um estudo sobre as dinâmicas de conselhos de saúde da cidade de São Paulo. Novos estud. [internet]. 2010 [acesso em 2016 out 21]; 86:121-139. Disponível em: http://www.scielo.br/pdf/nec/n86/n86a07.pdf.

27. Matuoka RI, Ogata MN. Análise qualitativa dos conselhos locais da Atenção Básica de São Carlos: a dinâmica de funcionamento e participação. Rev. APS. [internet]. 2010 [acesso em 2016 out 21]; 13(4):396405. Disponível em: https://periodicos.ufjf.br/index. php/aps/article/view/14395.

28. Matos AR. Democracia, participação cidadã e políticas públicas: uma avaliação a partir das ações de protesto. Configurações. [internet]. 2012 [acesso em
2017 fev 15]; 10:1-13. Disponível em: https://journals. openedition.org/configuracoes/1382.

29. Revista do Município de Vila Nova de Gaia. [internet]. 2016 [acesso em 2021 jan 22]; 2:3-11. Disponível em: https://issuu.com/cmgaia/docs/revista_cmgaia_04_2016/11.

30. Liga dos Amigos do Hospital de Ponta Delgada. 20 anos de interajuda. Ribeira Grande: Coingra; 2006. $271 \mathrm{p}$.

31. Urbinati N. Representation as advocacy - a study of Democratic Deliberation. PT. 2000; 28(6):758-786.

32. Vieira MB, Silva FC. Democracia deliberativa hoje: desafios e perspectivas. Rev. Bras. Ciênc. Polít. [internet]. 2013 [acesso em 2017 mar 21]; 10:151-194. Disponível em: http://www.scielo.br/pdf/rbcpol/n10/05. pdf.

33. Nunes JA, Ferreira P, Queirós F. Taking part: engaging knowledge on health in clinical encounters. Soc. sci. med. [internet]. 2014 [acesso em 2017 abr 15]; 123:194201. Disponível em: https://www.sciencedirect.com/ science/article/abs/pii/S0277953614004468.

34. Foucault M. Microfísica do Poder. Rio de Janeiro: Graal; 1990. 432 p.

35. Serapioni M. Os desafios da participação e da cidadania nos sistemas de saúde. Ciênc. Saúde Colet. [internet]. 2014 [acesso em 2017 abr 15]; 19(12):48294839. Disponível em: http://www.scielo.br/pdf/csc/ v19n12/1413-8123-csc-19-12-04829.pdf.

Recebido em 08/01/2020

Aprovado em 07/09/2020

Conflito de interesses: inexistente

Suporte financeiro: não houve 